\title{
Mechanism and risk factors of nausea and vomiting after TACE: a retrospective analysis
}

\author{
Haohao Lu*, Chuansheng Zheng, Bin Liang and Bin Xiong
}

\begin{abstract}
Purpose: The mechanism of postoperative nausea and vomiting after TACE is not clear. This study retrospectively analyzed the patient data to explore the mechanism and risk factors of postoperative nausea and vomiting after TACE.

Materials and methods: The data of 221 patients who underwent TACE in the interventional department from January 2019 to December 2020 were collected. Including: gender, age, liver function before TACE, etiology of liver cirrhosis, BCLC stage of hepatocellular carcinoma, preoperative use of analgesic drugs, preoperative limosis, previous history of vomiting, history of kinetosis, smoking history, history of drinking, chemotherapeutic drugs used during TACE, Dosage of lipiodol, and occurrence of postoperative nausea and vomiting.

Results: There were 116 cases of nausea after TACE, using binary logistic regression analysis, Sig: ALT0.003; ALP0.000; history of vomiting 0.043; kinetosis 0.006; history of alcohol consumption 0.011; preoperative limosis 0.006; dosage of lipiodol (5-10 mL) 0.029, dosage of lipiodol (>10 mL) 0.001.There were 89 cases of vomiting after TACE, all accompanied by nausea, Sig: ALP0.000; BCLC stage (B) 0.007; kinetosis 0.034; chemotherapeutic drugs 0.015; dosage of lipiodol (5-10 ml) 0.015, dosage of lipiodol (> $10 \mathrm{ml}$ ) 0.000; patients used analgesics before TACE 0.034.

Conclusions: Causes of post-TACE nausea and vomiting included operative trauma, aseptic inflammation caused by ischemia and hypoxia, chemotherapeutic drugs, ischemia of liver and bile duct, stress and pain during TACE, and patient factors. ALP, BCLC stage, kinetosis, chemotherapeutic drugs, dosage of lipiodol, and preoperative usage of analgesics were risk factors affecting nausea and vomiting after TACE.
\end{abstract}

Keywords: Nausea and vomiting, TACE, Risk factors, Regression analysis, Hepatocellular carcinoma, Embolic syndrome, Retrospective analysis

\section{Introduction}

Primary hepatocellular carcinoma is one of the malignant tumors with high morbidity and mortality worldwide [1-3], and because there are no obvious specific symptoms and signs in the early stage of the disease, most patients have lost the chance of surgery when

\footnotetext{
* Correspondence: 189062913@qq.com

Department of Radiology, Wuhan Union Hospital, Tongji Medical College, Huazhong University of Science and Technology, Jiefang Avenue \#1277, Wuhan 430022, China
}

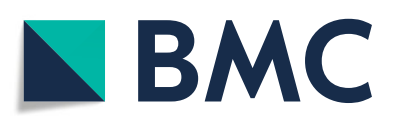

(c) The Author(s). 2021 Open Access This article is licensed under a Creative Commons Attribution 4.0 International License, which permits use, sharing, adaptation, distribution and reproduction in any medium or format, as long as you give appropriate credit to the original author(s) and the source, provide a link to the Creative Commons licence, and indicate if changes were made. The images or other third party material in this article are included in the article's Creative Commons licence, unless indicated otherwise in a credit line to the material. If material is not included in the article's Creative Commons licence and your intended use is not permitted by statutory regulation or exceeds the permitted use, you will need to obtain permission directly from the copyright holder. To view a copy of this licence, visit http://creativecommons.org/licenses/by/4.0/. The Creative Commons Public Domain Dedication waiver (http://creativecommons.org/publicdomain/zero/1.0/) applies to the data made available in this article, unless otherwise stated in a credit line to the data. detected. Transarterial chemoembolization (TACE) is currently one of the effective treatments for advanced hepatocellular carcinoma $[4,5]$. TACE was shown to improve median survival from 16 to 20 months [6]. Its main principle is to superselectively intubate the catheter into the feeding artery of the tumor after establishing a vascular access through femoral artery puncture and inject chemotherapeutic drugs and embolic agents [7]. On the one hand, chemotherapeutic drugs induce apoptosis and inhibit tumor cell proliferation; on the 
other hand, after tumor supply artery embolization, it leads to tumor cell ischemia, hypoxia and necrosis. TACE is effective in the treatment of liver cancer and plays a very important role in the treatment of hepatocellular carcinoma [8]. The most common side effects after TACE are embolic syndrome, including pain, fever, nausea and vomiting [9-11]. Malignant vomiting, in particular, is one of the major problems faced in clinical practice, which needs to be paid attention to by patients and doctors. Nausea and vomiting will increase the psychological and physical burden of patients, increase the suffering of patients and reduce the compliance of patients with treatment. Severe nausea and vomiting, can lead to water and electrolyte imbalance in patients, prolong hospital stay, and increase treatment costs [12]. At the same time, patients with hepatocellular carcinoma are mostly associated with cirrhosis and gastric esophageal varices, and severe nausea and vomiting will lead to gastric esophageal variceal bleeding, leading to death of patients. The mechanism of postoperative nausea and vomiting after TACE is not clear. This study retrospectively analyzed the patient data to explore the mechanism and risk factors of postoperative nausea and vomiting after TACE.

\section{Materials and methods}

\section{General information}

The data of 221 patients who underwent TACE in the Department of Intervention, Union Hospital, Tongji Medical College, Huazhong University of Science and Technology from January 2019 to December 2020 were collected. Inclusion criteria (1) Clinical or pathological diagnosis of primary hepatocellular carcinoma; (2) TACE treatment $\leq 2$ times; (3) Child-Pugh classification of liver function [13] A or B, performance status score (ECOG) 0-1; (3) Aged 18-70 years old; (4) No use of molecular targeted drugs or immunotherapy; (5) No central nervous system disease, intestinal obstruction and other primary diseases that can lead to nausea and vomiting. Exclusion criteria: (1) Child-Pugh classification of liver function $C$, performance status score (ECOG) $\geq 2$; (2) severe coagulopathy and can not be corrected; (3) cachexia or extensive distant metastasis of the tumor; (4) complete portal vein occlusion and collateral vessels; (5) renal insufficiency.

\section{Method}

Routine preparation, disinfection, draping. After local anesthesia with $2 \%$ lidocaine, the right femoral artery was punctured using the Seldinger technique and a 5F vascular sheath was placed. The feeding artery of the tumor was identified by catheterization with a $5 \mathrm{~F}$ Yashino catheter to the celiac trunk and superior mesenteric artery for angiography. Then 2.7F microcatheter was superselectively cannulated into the tumor feeding artery, appropriate amount of Lipiodol + chemotherapeutic emulsion was slowly injected for embolization, and 300-500 um gelatin sponge particles were supplemented for embolization. The embolization endpoint was forward blood flow stasis in the tumor feeding artery. Chemotherapeutic drugs used during surgery are divided into two types: (1) lobaplatin $50 \mathrm{mg}$; (2) epirubicin $30 \mathrm{mg}$. The amount of iodized oil used was 5-20 ml.Evaluation criteria for nausea and vomiting: Common Terminology Criteria for Adverse Events (CTCAE 5.0).

Materials and drugs used for TACE: $5 \mathrm{~F}$ vascular sheath (TERUMO5F-10CM, Terumo, Japan), 0.035 in. (RFGA35153M, Terumo, Japan), 5F Yashino catheter (Terumo, Japan), 2.7F microcatheter (Terumo, Japan). Lobaplatin (GYZZ H20050308, Hainan Chang'an International Pharmaceutical Co., Ltd.), epirubicin (GYZZ H19990280, Zhejiang Hisun Pharmaceutical Co., Ltd.).

SPSS software (Version 24.0, IBM, Armonk, NewYork) was used to statistically analyze the data. Enumeration data are expressed by number of cases (percentage). Measurement data were expressed as mean \pm standard deviation. The models are multivariate, Binary logistic regression analysis was used, method used Enter, the indicator (first) was used for comparison, and $P<0.05$ was considered statistically significant.

\section{Results}

\section{Basic information}

There were 136 (61.5\%) male patients and 85 (38.5\%) female patients. The age ranged from 24 to 69 years, with an average of $47.9 \pm 12.0$ years. Seventeen patients $(7.7 \%)$ were aged $\leq 30$ years, $133(60.2 \%)$ were aged $30-55$ years, and $71(32.1 \%)$ were aged $\geq 55$ years.

Preoperative Child-Pugh classification of liver function: 157 patients (71\%) in class A and 64 patients (29\%) in class B. ALT: $11-96 \mathrm{U} / \mathrm{L}$, with an average of $44.2 \pm$ 19.0 U/L. AST: 8-86 U/L, with an average of $42.0 \pm 17.4$ U/L. ALP: 40-198 U/L, with an average of $92.0 \pm 26.8 \mathrm{U} /$ L (Table 1). The causes of cirrhosis were hepatitis B in 196 patients (88.7\%) and hepatitis $C$ in 25 patients (11.3\%). BCLC stage (12): 29 patients (13.1\%) in stage A, 123 patients $(55.7 \%)$ in stage B, and 69 patients $(31.2 \%)$ in stage C. Preoperative analgesic drugs were used in 64 patients (29\%) and no analgesic drugs were used in 157

Table 1 Descriptive statistics

\begin{tabular}{lllll}
\hline & Minimum & Maximum & Mean & Std. Deviation \\
\hline Age & 24 & 69 & 47.92 & 11.998 \\
ALT(U/L) & 11 & 96 & 44.22 & 19.015 \\
AST(U/L) & 8 & 86 & 42.06 & 17.366 \\
ALP(U/L) & 40 & 198 & 92.00 & 26.774 \\
\hline
\end{tabular}


Table 2 General information of patients

\begin{tabular}{|c|c|c|}
\hline & Frequency & Percen \\
\hline \multicolumn{3}{|l|}{ Gender } \\
\hline Female & 112 & 50.7 \\
\hline Male & 109 & 49.3 \\
\hline \multicolumn{3}{|l|}{ Age group } \\
\hline$\leq 30$ & 17 & 7.7 \\
\hline $30-55$ & 133 & 60.2 \\
\hline$\geq 55$ & 71 & 32.1 \\
\hline \multicolumn{3}{|c|}{ Child-Pugh Classification } \\
\hline A & 157 & 71.0 \\
\hline B & 64 & 29.0 \\
\hline \multicolumn{3}{|c|}{ Etiology of liver cirrhosis } \\
\hline Hepatitis B & 196 & 88.7 \\
\hline Hepatitis C & 25 & 11.3 \\
\hline \multicolumn{3}{|l|}{ BCLC stage } \\
\hline A & 29 & 13.1 \\
\hline B & 123 & 55.7 \\
\hline$C$ & 69 & 31.2 \\
\hline \multicolumn{3}{|c|}{ History of vomiting } \\
\hline No & 181 & 81.9 \\
\hline Yes & 40 & 18.1 \\
\hline \multicolumn{3}{|l|}{ Kinetosis } \\
\hline No & 177 & 80.1 \\
\hline Yes & 44 & 19.9 \\
\hline \multicolumn{3}{|c|}{ Smoking history } \\
\hline No & 179 & 81.0 \\
\hline Yes & 42 & 19.0 \\
\hline \multicolumn{3}{|c|}{ Alcohol history } \\
\hline No & 172 & 77.8 \\
\hline Yes & 49 & 22.2 \\
\hline \multicolumn{3}{|c|}{ Use of analgesics } \\
\hline No & 157 & 71.0 \\
\hline Yes & 64 & 29.0 \\
\hline \multicolumn{3}{|c|}{ Chemotherapeutic drugs } \\
\hline Lobaplatin & 109 & 49.3 \\
\hline Epirubicin & 112 & 50.7 \\
\hline \multicolumn{3}{|c|}{ Dosage of Lipiodol } \\
\hline$<5 \mathrm{ml}$ & 81 & 36.7 \\
\hline $5-10 \mathrm{ml}$ & 85 & 38.5 \\
\hline$>10 \mathrm{ml}$ & 55 & 24.9 \\
\hline \multicolumn{3}{|c|}{ Limosis before operation } \\
\hline No & 110 & 49.8 \\
\hline Yes & 111 & 50.2 \\
\hline
\end{tabular}

Table 2 General information of patients (Continued)

\begin{tabular}{lll}
\hline & Frequency & Percent \\
\hline Postoperative pain & & \\
No & 112 & 50.7 \\
Yes & 109 & 49.3 \\
\hline
\end{tabular}

patients (71\%). Preoperative limosis was performed in 111 patients $(50.2 \%)$ and non-limosis in 110 patients (49.8\%). Forty patients (18.1\%) had a previous history of vomiting and 181 patients (81.9\%) had no history of vomiting. Forty-four patients (19.9\%) had a history of kinetosis and 177 patients (80.1\%) had no history of kinetosis. Forty-two patients (19\%) had a smoking history and 179 patients (81\%) had no smoking history. Forty-nine patients $(22.2 \%)$ had a history of alcohol consumption and 172 patients $(77.8 \%)$ had no history of alcohol consumption. Chemotherapeutic drugs were used during surgery: lobaplatin in 109 patients (49.3\%) and epirubicin in 112 patients (50.7\%). The amount of lipiodol used was: $<5 \mathrm{ml}$ in 81 patients $(36.7 \%), 5-10 \mathrm{ml}$ in 85 patients $(38.5 \%)$, and $>10 \mathrm{ml}$ in 55 patients $(24.9 \%)$. Postoperative patients had pain in 109 patients (49.3\%) (Table 2). Postoperative nausea occurred in 116 patients (52.5\%). Postoperative vomiting occurred in 89 patients (40.3\%), and patients with postoperative vomiting were accompanied by nausea (Table 3) (Figs. 1 and 2).

\section{Incidence of nausea after TACE}

Nausea occurred in 116 patients (52.5\%) after TACE. Binary logistic regression analysis (Table 4) was used, with the method using enter and the contrast using indicator (first).

$\operatorname{Sig}(P$ value $):$ ALT0.003; ALP0.000; history of vomiting 0.043; kinetosis 0.006; history of alcohol consumption 0.011 ; preoperative limosis 0.006 ; dosage of lipiodol (5$10 \mathrm{~mL}$ ) 0.029, dosage of lipiodol (>10 mL) 0.001. The above are risk factors for post-TACE nausea. $(P<0.05)$ OR values, Exp (B): ALT1.093; ALP0.894; history of vomiting 11.621; kinetosis 20.149; history of alcohol consumption 0.117; preoperative limosis 7.257; dosage of lipiodol (5-10 mL) 5.862, dosage of lipiodol (>10 mL) 43.920 .

\section{Incidence of vomiting after TACE}

Vomiting occurred in 89 patients (40.3\%) after TACE, all of whom had nausea. Binary logistic regression analysis (Table 5) was used, with the method using enter and the contrast using the indicator (first).

$\operatorname{Sig}(P$ value $)$ ALP0.000; BCLC stage (B) 0.007; kinetosis 0.034 ; chemotherapeutic drugs 0.015 ; dosage of lipiodol (5-10 ml) 0.015 , dosage of lipiodol $(>10 \mathrm{ml})$ 0.000 ; patients used analgesics before TACE 0.034 . 
Table 3 Incidence of nausea and vomiting after TACE

\begin{tabular}{lcc}
\hline & Frequency & Percent \\
\hline \multirow{3}{*}{ No } & Postoperative nausea \\
Yes & 105 & 47.5 \\
& 116 & 52.5 \\
No & Postoperative vomiting & \\
Yes & 132 & 59.7 \\
\hline
\end{tabular}

The above are risk factors for nausea and vomiting after TACE. $(P<0.05)$ OR values, Exp (B): ALP0.959; BCLC stage (B) 5.906; kinetosis s 2.997; chemotherapeutic drugs 0.357 ; dosage of lipiodol $(5-10 \mathrm{ml}) 3.196$, dosage of lipiodol (>10 ml) 7.396; patients used analgesics before TACE 0.402 .

\section{Discussion}

Nausea is a feeling of visceral discomfort that eventually reaches the climax of the response with vomiting. Vomiting is a protective reflex that refers to the process by which gastric contents are excreted from the body through the mouth. A variety of receptors have been found to trigger nausea and vomiting [14, 15]. (1) Visceral receptors: Visceral receptors are divided into mechanical and chemical receptors. Mechanical receptors are located in the gastrointestinal wall and are sensitive to traction stimulation of the gastrointestinal wall. Chemoreceptors are mainly located in the gastrointestinal mucosa and can sense changes in the internal environment of the digestive tract, irritation by drugs and poisons [16]. (2) Receptors of the area postrema: The area postrema is located on the dorsal surface of the medulla oblongata and at the level of the base latch of the

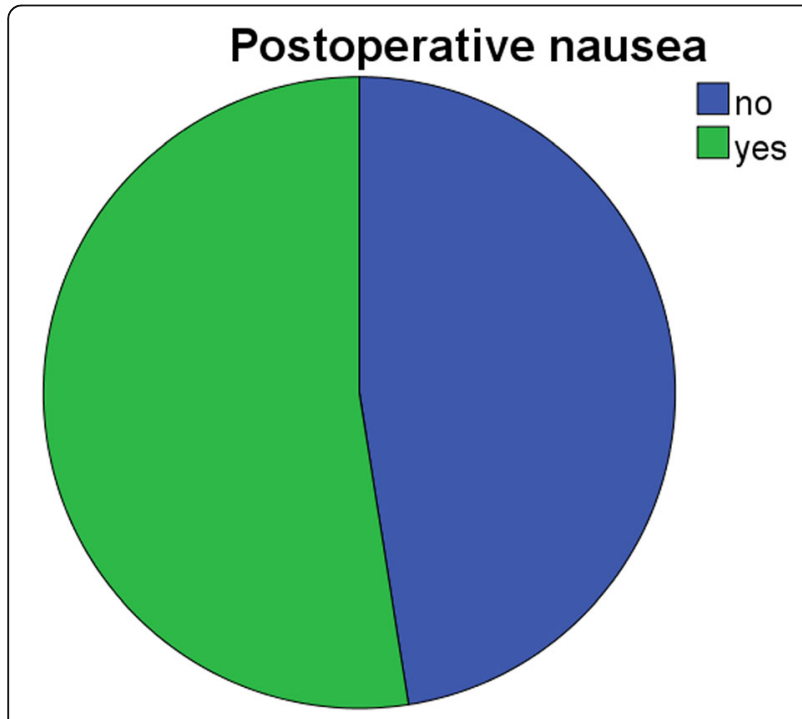

Fig. 1 Postoperative nausea occurred in 116 patients (52.5\%)

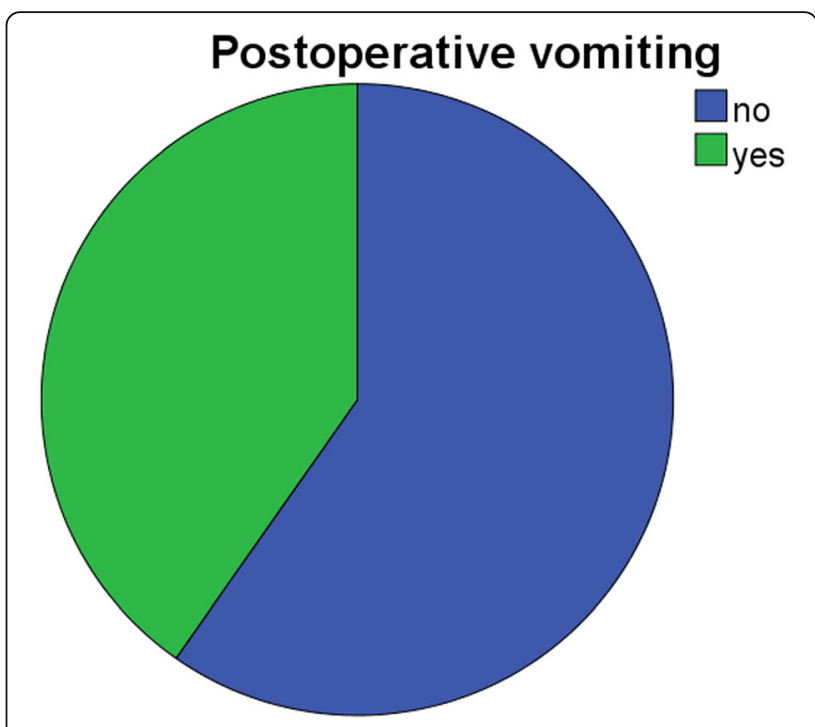

Fig. 2 Postoperative vomiting occurred in 89 patients (40.3\%), and patients with postoperative vomiting were accompanied by nausea

fourth ventricle. This structure is abundant and lacks the blood-brain barrier and the cerebrospinal fluid-brain barrier. Chemicals, certain peptides in the body, etc., can act on receptors in the area postrema to cause vomiting. (3) Vestibular Receptors: Vestibular receptors are abnormally stimulated (motor stimulation, position change) and can cause nausea and vomiting, but studies have shown that there is insufficient evidence that vestibular receptors play a direct role in vomiting caused by drug stimulation. (4) Descending signals in higher centers: Studies have found that certain psychiatric factors, hypotension, pain, increased intracranial pressure, and craniocerebral injury act descending on vomiting centers through different regions of the cerebral cortex, causing nausea and vomiting [17]. The mechanism of nausea and vomiting is not fully understood, but a variety of transmitters and receptors are known to be involved in this process, such as acetylcholine, epinephrine, norepinephrine, dopamine, histamine, serotonin, substance P, Yaminobutyric acid, and opioid receptors [18, 19].

\section{Postoperative nausea and vomiting (PONV)}

PONV is a common complication after surgical procedures, with an incidence of approximately 30\% [20]. Without prevention, the incidence of PONV in the population is as high as $80 \%$ [21]. Common causes of PONV are: (1) anesthetic factors. The use of inhaled anesthetics and opioids, is an important factor causing PONV. (2) Surgical factors. Surgical trauma and inflammatory reactions, which can cause the release of serotonin, substance $\mathrm{P}$, and other transmitters, result in nausea and vomiting. Studies have shown that the longer the operation time, the higher the risk of PONV. The 
Table 4 Postoperative nausea after TACE, Binary logistic regression analysis

Hosmer and Lemeshow Test
\begin{tabular}{|l|l|l|l|}
\hline Step & Chi-square & df & Sig. \\
\hline 1 & 19.953 & 8 & .611 \\
\hline
\end{tabular}

Variables in the Equation

\begin{tabular}{|c|c|c|c|c|c|c|}
\hline & \multirow[t]{2}{*}{ B } & \multirow[t]{2}{*}{ Sig. } & \multirow[t]{2}{*}{ OR } & \multicolumn{2}{|c|}{ 95\% C.I.for OR } \\
\hline & & & & & Lower & Upper \\
\hline \multirow{24}{*}{ Step 1a } & Gender(1) & .070 & .917 & 1.073 & .287 & 4.015 \\
\hline & $\operatorname{Age} \operatorname{group}(<30 y)$ & & .012 & & & \\
\hline & Age $\operatorname{group}(30-55 y)(1)$ & 1.312 & .266 & 3.713 & .368 & 37.470 \\
\hline & Age group(>55y) (2) & -1.117 & .385 & 327 & .026 & 4.076 \\
\hline & Child-Pugh Classification (1) & 1.473 & 138 & 4.363 & .623 & 30.567 \\
\hline & ALT & .089 & .003 & 1.093 & 1.032 & 1.158 \\
\hline & AST & -.015 & .582 & .985 & .934 & 1.039 \\
\hline & ALP & -.112 & .000 & .894 & .855 & .935 \\
\hline & Etiology of liver cirrhosis (1) & -.365 & .698 & .694 & .110 & 4.395 \\
\hline & BCLC stage(BCLC A) & & .566 & & & \\
\hline & BCLC stage (BCLC B) (1) & .041 & .972 & 1.042 & .102 & 10.626 \\
\hline & BCLC stage(BCLC C) (2) & .888 & .521 & 2.430 & .161 & 36.631 \\
\hline & History of vomiting (1) & 2.453 & .043 & 11.621 & 1.082 & 124.804 \\
\hline & Kinetosis (1) & 3.003 & .006 & 20.149 & 2.323 & 174.761 \\
\hline & Smoking history (1) & -.278 & .782 & .757 & .106 & 5.432 \\
\hline & Alcohol history (1) & -2.150 & .011 & .117 & .022 & .605 \\
\hline & Chemotherapeutic drugs (1) & -.756 & .315 & .470 & 108 & 2.053 \\
\hline & Dosage of Lipiodol( $<5 \mathrm{ml})$ & & .002 & & & \\
\hline & $\begin{array}{l}\text { Dosage of Lipiodol }(5-10 \mathrm{ml}) \\
\text { (1) }\end{array}$ & 1.768 & .029 & 5.862 & 1.198 & 28.672 \\
\hline & Dosage of Lipiodol(>10ml) (2) & 3.782 & .001 & 43.920 & 5.140 & 375.271 \\
\hline & Use of analgesics (1) & .179 & .800 & 1.196 & .299 & 4.787 \\
\hline & Postoperative pain (1) & 1.212 & .089 & 3.362 & .831 & 13.604 \\
\hline & Limosis before operation (1) & 1.982 & .006 & 7.257 & 1.780 & 29.594 \\
\hline & Constant & 2.972 & .132 & 19.527 & & \\
\hline
\end{tabular}

type of surgery is also one of the causes of PONV, such as hepatobiliary surgery, gynecological surgery, and otolaryngological surgery are more likely to develop PONV than other types of surgery [22]. (3) Patient factors. Young women, no smoking history, history of PONV, and history of kinetosis were risk factors confirmed by the study. Other possible risk factors are BMI, American Society of Anesthesiologists (ASA) classification, history of migraine, and menstrual cycle [23].

Chemotherapy-induced nausea and vomiting (CINV) Chemotherapy plays an important role in the treatment of malignant tumors, and CINV is one of the common adverse reactions of chemotherapy. Chemotherapeutic drugs can act directly on the intestinal mucosa through the intestinal lumen, or activate the chemoreceptor trigger zone through the blood circulation, which promotes the release of a variety of neurotransmitters and acts on the vomiting center, resulting in nausea and vomiting $[24,25]$. The National Comprehensive Cancer Network classifies emetogenic antineoplastic agents into four levels [26], and different antineoplastic agents, have different emetogenic risks.

\section{Mechanism of nausea and vomiting after TACE}

Similar to surgery, TACE is an invasive treatment that may cause pain and inflammatory reaction of organs, and patients may use analgesics. The differences between TACE and surgical operation include: (1) TACE is usually a local anesthesia operation, which is generally 
Table 5 Postoperative vomiting after TACE, Binary logistic regression analysis

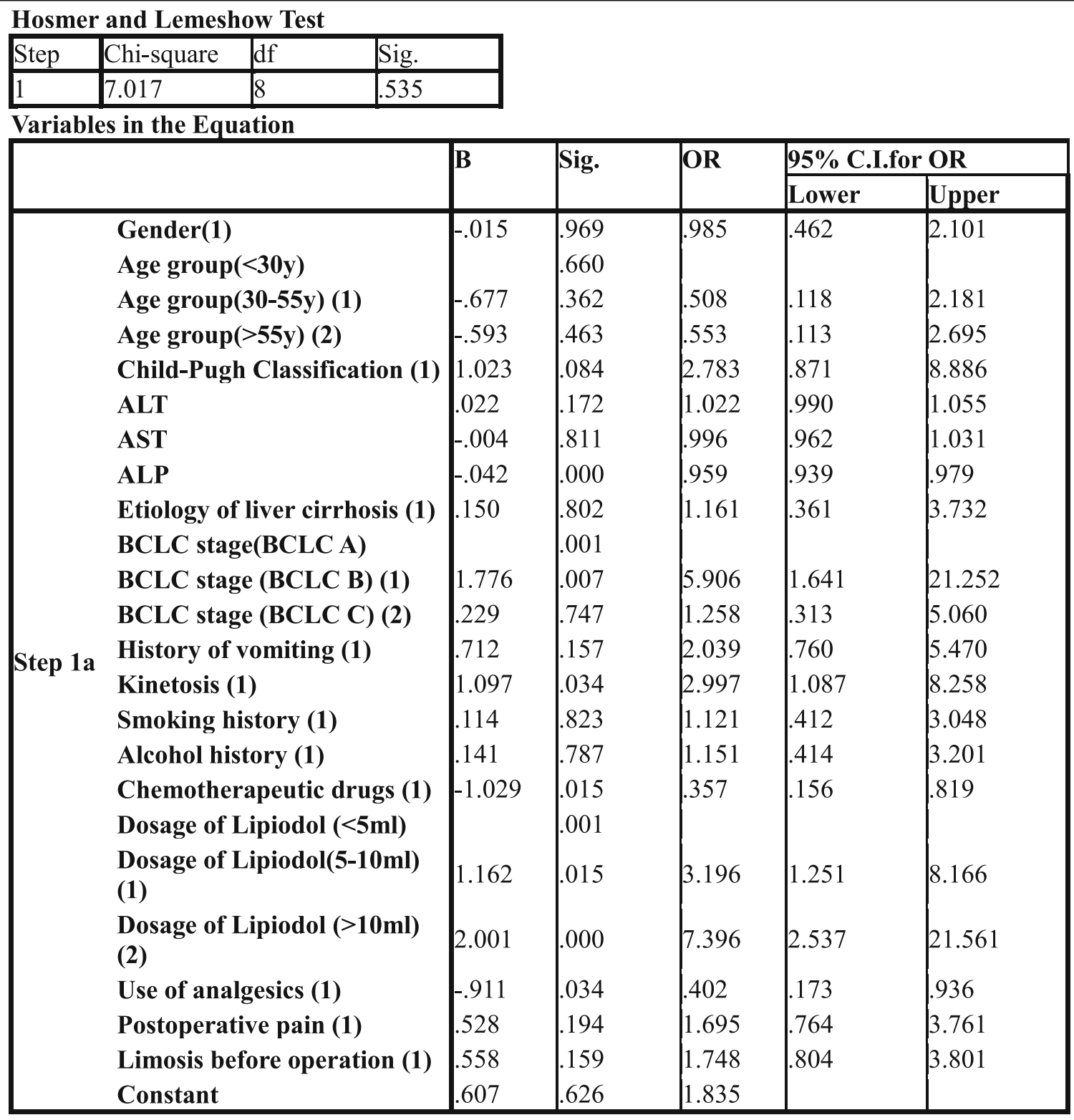

a puncture site injection of local anesthetics and does not require the use of inhaled anesthetics; (2) TACE usually uses chemotherapeutic drugs; chemotherapeutic drugs are generally not used through vascular route during surgery; (3) TACE embolizes tumor feeding artery, which will lead to tumor ischemia, hypoxia, necrosis and aseptic inflammation; while surgical operation includes organ trauma and traction. Similar to chemotherapy, chemotherapeutic agents will be used during TACE. However, the dose of chemotherapeutic drugs used during surgery was significantly lower in TACE than in chemotherapy. Moreover, compared with chemotherapy, TACE performed embolization of tumor vessels, resulting in ischemia of the tissue. Because of the differences between TACE and surgery and chemotherapy, the causes of nausea and vomiting after TACE are not exactly the same as those of PONV and CINV. We believe that the causes of nausea and vomiting after TACE include: (1) trauma caused by operation, aseptic inflammation caused by ischemia and hypoxia, inducing the release of a variety of transmitters; (2) intraoperative use of chemotherapeutic drugs, through the blood circulation, stimulating the chemoreceptors of the gastrointestinal tract; especially during TACE, chemotherapeutic drugs are often injected through the celiac trunk or superior mesenteric artery branches, while the celiac trunk or superior mesenteric artery has vascular branches directly supplying the gastrointestinal tract; epirubicin and 
platinum used during TACE are chemotherapeutic drugs with moderate to high emetic risk; (3) the organs involved in TACE are the liver and gallbladder, and hepatic artery embolization will lead to hepatobiliary ischemia; similar to the causes of PONV, hepatobiliary surgery is more likely to have postoperative nausea and vomiting than other surgeries; (4) stress and pain during TACE will lead to the release of dopamine, epinephrine and other transmitters, leading to nausea and vomiting; (5) patient factors, such as young women, no history of smoking, history of PONV, and history of kinetosis [27].

\section{Risk factors of nausea and vomiting after TACE}

Binary logistic regression analysis showed that ALP, BCLC stage, kinetosis, chemotherapeutic drugs, dosage of lipiodol and preoperative use of analgesics were risk factors affecting nausea and vomiting after TACE. Similar to PONV and CINV, the history of kinetosis was a risk factor for nausea and vomiting after TACE [28], and the OR for nausea and vomiting after TACE was 2.997 in patients with a history of kinetosis relative to those without a history. Compared with BCLC A stage, BCLC $B$ stage has higher risk of postoperative nausea and vomiting, and may be multinodular liver cancer or massive liver cancer in BCLC B stage, with more dosage of embolic agent and wider embolization range. Lipiodol dose is a risk factor for nausea and vomiting after TACE. It was considered that the more lipiodol is used, the wider the embolization range, the more severe the tissue ischemia and hypoxia, aseptic inflammation and more transmitters are released. Kabuki M [29] etal shows that the multivariate logistic regression model with a predictive success of $92.4 \%$ for vomiting identified significant associations between female gender (odds ratio: 3.73, $p<0.001)$, the number of tumors $(1.29, p<0.01)$, and administration of pentazocine $(11.70, p<0.05)$ with the risk of vomiting. The results of this study showed that chemotherapeutic drugs were the risk factors of postoperative nausea and vomiting after TACE. The incidence of postoperative nausea and vomiting was higher in patients who used lobaplatin during the operation. Several studies showed that the use of lobaplatin emulsion for embolization resulted in a higher tumor necrosis rate. Possibly, due to this reason, the more necrotic substances were released after TACE, the more severe the inflammatory response, and the risk of postoperative nausea and vomiting. The results showed that ALP was a risk factor for nausea and vomiting after TACE. The risk of postoperative nausea and vomiting in patients with low ALP level was consistent with the results of Wang [27], Wang etal.found out patients who developed vomiting, compared to those who did not, also had lower levels $(<100 \mathrm{IU} / \mathrm{L})$ of serum ALP $(112.52 \pm 62.63$ vs. $160.10 \pm 127.80$, respectively, $p=0.010)$, and serum alanine transferase (ALT) $(35.61 \pm 22.87$ vs. $44.97 \pm$ 29.62 , respectively, $p=0.045)$. wang etal. Observed that lower levels of ALP $(<100 \mathrm{IU} / \mathrm{L})$ occurred more frequently in patients with lower levels of ALT, AST and LDH ( $p=0.002, p=0.000$ and $p=0.001$, respectively). But why patients with better liver function are more likely to experience nausea and vomiting after TACE, the reason for this remains unclear. Preoperative use of analgesic drugs was the risk factor of nausea and vomiting after TACE $(\mathrm{OR}=0.402)$, which was inconsistent with PONV. The reason was analyzed that in this group of patients with hepatocellular carcinoma, oral drugs were used for analgesia, and non-steroidal antiinflammatory drugs were mainly used. Non-steroidal anti-inflammatory drugs could reduce the aseptic inflammation caused by postoperative tumor necrosis. At the same time, good analgesia could reduce the stress response of patients, so the risk of postoperative nausea and vomiting was lower.

\section{Conclusions}

There were multiple causes for nausea and vomiting after TACE, including operative trauma, aseptic inflammation caused by ischemia and hypoxia, intraoperative use of chemotherapeutic drugs, ischemia of liver and bile duct, stress and pain during TACE, and patient factors (such as young women, no smoking history, history of PONV, and history of kinetosis). The above are all possible causes of nausea and vomiting after TACE, and among these factors, ALP, BCLC stage, chemotherapeutic drugs, dosage of lipiodol, and preoperative patient use of analgesics were risk factors affecting nausea and vomiting after TACE. Careful evaluation of patients' factors before TACE and early preventive intervention can reduce patients' psychological and physical burden, reduce perioperative risks, improve patients' treatment compliance and reduce patients' hospitalization costs.

The shortcomings of this study were that the data were from a single center and the sample size was limited. A multi-center and large-sample study was feasible in the later stage. The risk assessment table of nausea and vomiting before TACE could be developed according to the risk factors in the later stage to provide more help for clinical work.

\footnotetext{
Acknowledgements

Thank Pro. Guohui Liu for his help in English writing. Thank Dr. Wei Wang for his help in data collection. Thank Dr. Kang Zhang for his help in reference.

Thank you for all those who offer help and support in this research.
}

\section{Authors' contributions}

Haohao Lu have made substantial contributions to the conception and design of the work,and the acquisition, analysis of data, as well as manuscript writing. Chuansheng Zheng have made contributions to the design of the work. Bin Liang have made contributions to the acquisition, analysis of data. Bin Xiong have made contributions to analysis,

interpretation of data,and manuscript writing. All authors have agreed both 
to be personally accountable for the author's own contributions and to ensure that questions related to the accuracy or integrity of any part of the work. Haohao Lu is corresponding author,and responsible for ensuring that all listed authors have approved the manuscript before submission.

\section{Funding}

No funding is provided in this study.

\section{Availability of data and materials}

The datasets used and analysed during the current study are available from the corresponding author on reasonable request.

\section{Declarations}

\section{Ethics approval and consent to participate}

The medical ethics committee of our college (Union Hospital,Tongji Medical College,Huazhong University of science and technology, Wuhan, Hubei Province) approved the retrospective study and gave up the written informed consent. Although the ethics committee gave up the written consent, for the safety and rationality of the research, we still signed the informed consent for all the participants. During follow-up, we informed patients about the study and they agreed to use their data. We confirm that all methods were performed in accordance with the relevant guidelines and Declaration of Helsinki.

\section{Consent for publication}

All participants' information, images and inspection results are agreed to be published and have obtained written consent. The details, images will be freely available on the internet and may be seen by the general public. The consent form is available if requested. These patients have not been reported in any other submission by anyone.

\section{Competing interests}

We declare that we have no financial and personal relationships with other people or organizations that can inappropriately influence our work, there is no professional or other personal interest of any nature or kind in any product, service and company that could be construed as influencing the position presented in this manuscript.

Received: 16 March 2021 Accepted: 20 April 2021

Published online: 07 May 2021

\section{References}

1. Hartke J, Johnson M, Ghabril M. The diagnosis and treatment of hepatocellular carcinoma. Semin Diagn Pathol. 2017;34(2):153-9. https://doi. org/10.1053/j.semdp.2016.12.011 Epub 2016 Dec 20. PMID: 28108047.

2. Clark T, Maximin S, Meier J, Pokharel S, Bhargava P. Hepatocellular carcinoma: review of epidemiology, screening, imaging diagnosis, response assessment, and treatment. Curr Probl Diagn Radiol. 2015;44(6):479-86. https://doi.org/10.1067/j.cpradiol.2015.04.004 Epub 2015 Apr 16. PMID: 25979220.

3. Budny A, Kozłowski P, Kamińska M, Jankiewicz M, Kolak A, Budny B, et al. Epidemiologia i czynniki ryzyka rozwoju raka wątrobowokomórkowego [Epidemiology and risk factors of hepatocellular carcinoma]. Pol Merkur Lekarski. 2017;43(255):133-9 Polish. PMID: 28987047.

4. Raoul JL, Forner A, Bolondi L, Cheung T, Kloeckner R, de Baere T. Updated use of TACE for hepatocellular carcinoma treatment: how and when to use it based on clinical evidence. Cancer Treat Rev. 2019;72:28-36. https://doi. org/10.1016/j.ctrv.2018.11.002 Epub 2018 Nov 12. PMID: 30447470.

5. Han K, Kim JH. Transarterial chemoembolization in hepatocellular carcinoma treatment: Barcelona clinic liver cancer staging system. World J Gastroenterol. 2015;21(36):10327-35. https://doi.org/10.3748/wjg.v21.i36.1 0327 PMID: 26420959; PMCID: PMC4579879.

6. Lencioni R, Petruzzi $P$, Crocetti L. Chemoembolization of hepatocellular carcinoma. Semin Intervent Radiol. 2013;30(1):3-11. https://doi.org/10.1055/ s-0033-1333648 PMID: 24436512; PMCID: PMC3700789

7. Sacco R, Tapete G, Simonetti N, Sellitri R, Natali V, Melissari S, et al, Transarterial chemoembolization for the treatment of hepatocellular carcinoma: a review. J Hepatocell Carcinoma. 2017:4:105-10. https://doi. org/10.2147/JHC.S103661 PMID: 28795053; PMCID: PMC5538681.
8. Imai N, Ishigami M, Ishizu Y, Kuzuya T, Honda T, Hayashi K, et al. Transarteria chemoembolization for hepatocellular carcinoma: A review of techniques. World J Hepatol. 2014;6(12):844-50. https://doi.org/10.4254/wjh.v6.i12.844 PMID: 25544871; PMCID: PMC4269903.

9. Vogl TJ, Zangos S, Balzer JO, Nabil M, Rao P, Eichler K, et al. Transarterielle Chemoembolisation (TACE) des hepatozellulären Karzinoms: Technik, Indikationsstellung und Ergebnisse [Transarterial chemoembolization (TACE) in hepatocellular carcinoma: technique, indication and results]. Rofo. 2007; 179(11):1113-26. https://doi.org/10.1055/s-2007-963285 German. PMID: 17948190.

10. Marcacuzco Quinto A, Nutu OA, San Román Manso R, Justo Alonso I, Calvo Pulido J, Manrique Municio A, et al. Complications of transarterial chemoembolization (TACE) in the treatment of liver tumors. Cir Esp. 2018; 96(9):560-7. https://doi.org/10.1016/j.ciresp.2018.06.004 English, Spanish. Epub 2018 Aug 3. PMID: 30082086.

11. Arslan M, Degirmencioglu S. Risk factors for Postembolization syndrome after Transcatheter arterial chemoembolization. Curr Med Imaging Rev. 2019;15(4):380-5. https://doi.org/10.2174/1573405615666181122145330 PMID: 31989907.

12. Blackburn H, West S. Management of Postembolization Syndrome Following Hepatic Transarterial Chemoembolization for primary or metastatic liver Cancer. Cancer Nurs. 2016;39(5):E1-E18. https://doi.org/10.1097/NCC. 0000000000000302 PMID: 26484962.

13. Tsoris A, Marlar CA. Use Of The Child Pugh Score In Liver Disease. 2020 May 17. In: StatPearls. Treasure Island: StatPearls Publishing; 2020. PMID: 31194448

14. Horn CC, Wallisch WJ, Homanics GE, Williams JP. Pathophysiological and neurochemical mechanisms of postoperative nausea and vomiting. Eur J Pharmacol. 2014;722:55-66. https://doi.org/10.1016/j.ejphar.2013.10.037 Epub 2013 Oct 26. PMID: 24495419; PMCID: PMC3915298.

15. Kenward H, Pelligand L, Savary-Bataille K, Elliott J. Nausea: current knowledge of mechanisms, measurement and clinical impact. Vet J. 2015; 203(1):36-43. https://doi.org/10.1016/j.tvjl.2014.10.007 Epub 2014 Oct 14. PMID: 25453240

16. Cangemi DJ, Kuo B. Practical perspectives in the treatment of nausea and vomiting. J Clin Gastroenterol. 2019;53(3):170-8. https://doi.org/10.1097/ MCG.0000000000001164 PMID: 30614944

17. Singh $P$, Kuo B. Central aspects of nausea and vomiting in $\mathrm{Gl}$ disorders. Curr Treat Options Gastroenterol. 2016;14(4):444-51. https://doi.org/10.1007/s11 938-016-0107-x PMID: 27734216.

18. Becker DE. Nausea, vomiting, and hiccups: a review of mechanisms and treatment. Anesth Prog. 2010;57(4):150-6. https://doi.org/10.2344/0003-3 006-57.4.150 quiz 157. PMID: 21174569; PMCID: PMC3006663.

19. Wiesmann $T$, Kranke $P$, Eberhart L. Postoperative nausea and vomiting - a narrative review of pathophysiology, pharmacotherapy and clinical management strategies. Expert Opin Pharmacother. 2015;16(7):1069-77. https://doi.org/10.1517/14656566.2015.1033398 Epub 2015 Apr 12. PMID: 25866213.

20. Cao X, White PF, Ma H. An update on the management of postoperative nausea and vomiting. J Anesth. 2017;31(4):617-26. https://doi.org/10.1007/ s00540-017-2363-x Epub 2017 Apr 28. PMID: 28455599.

21. Aroke EN, Hicks TL. Pharmacogenetics of postoperative nausea and vomiting. J Perianesth Nurs. 2019;34(6):1088-105. https://doi.org/10.1016/j. jopan.2019.03.007 Epub 2019 Jun 18. PMID: 31227296.

22. Ma K, Wu X, Chen Y, Yuan H. Effect of multimodal intervention on postoperative nausea and vomiting in patients undergoing gynecological laparoscopy. J Int Med Res. 2019;47(5):2026-33. https://doi.org/10.1177/03 00060519835700 Epub 2019 Mar 18. PMID: 30885027; PMCID: PMC6567741.

23. Golembiewski J, Chernin E, Chopra T. Prevention and treatment of postoperative nausea and vomiting. Am J Health Syst Pharm. 2005;62(12): 1247-60. https://doi.org/10.1093/ajhp/62.12.1247 quiz 1261-2. PMID: 15947124

24. Wickham RJ. Revisiting the physiology of nausea and vomiting-challenging the paradigm. Support Care Cancer. 2020;28(1):13-21. https://doi.org/10.1 007/s00520-019-05012-8 Epub 2019 Aug 6. PMID: 31388745.

25. Simino GPR, Reis IA, Acurcio FA, Andrade EIG, Brazil NML, Cherchiglia ML. Risk factors associated with antineoplastic chemotherapy-induced nausea and vomiting. Rev Saude Publica. 2020;54:106. https://doi.org/10.11606/s151 8-8787.2020054002178 PMID: 33175025; PMCID: PMC7647467.

26. Berger MJ, Ettinger DS, Aston J, Barbour S, Bergsbaken J, Bierman PJ, et al. NCCN guidelines insights: Antiemesis, version 2.2017. J Natl Compr Cancer 
Netw. 2017;15(7):883-93. https://doi.org/10.6004/jnccn.2017.0117 PMID: 28687576.

27. Wang SY, Zhu WH, Vargulick S, Lin SB, Meng ZQ. Nausea and vomiting after transcatheter arterial chemoembolization for hepatocellular carcinoma: incidence and risk factor analysis. Asian Pac J Cancer Prev. 2013;14(10):59956000. https://doi.org/10.7314/apjcp.2013.14.10.5995 PMID: 24289614.

28. Son J, Yoon $\mathrm{H}$. Factors affecting postoperative nausea and vomiting in surgical patients. J Perianesth Nurs. 2018;33(4):461-70. https://doi.org/10.101 6/j.jopan.2016.02.012 Epub 2017 Apr 25. PMID: 30077290.

29. Kabuki M, Higashihara H, Kakuda M, Fujita Y, Masuda J, Kin K, et al. Impact of preventive administration of antiemetic drugs on risk of acute nausea and vomiting induced by transcatheter arterial chemoembolization in patients with hepatocellular carcinomas - a retrospective study. Gan To Kagaku Ryoho. 2013;40(2):197-201 Japanese. PMID: 23411955.

\section{Publisher's Note}

Springer Nature remains neutral with regard to jurisdictional claims in published maps and institutional affiliations.

Ready to submit your research? Choose BMC and benefit from:

- fast, convenient online submission

- thorough peer review by experienced researchers in your field

- rapid publication on acceptance

- support for research data, including large and complex data types

- gold Open Access which fosters wider collaboration and increased citations

- maximum visibility for your research: over $100 \mathrm{M}$ website views per year

At $B M C$, research is always in progress.

Learn more biomedcentral.com/submissions 